Trinity University

Digital Commons @ Trinity

Religion Faculty Research

Religion Department

2012

\title{
Translating the Bible Into Pictures
}

Rubén R. Dupertuis

Trinity University, rdupertu@trinity.edu

Follow this and additional works at: https://digitalcommons.trinity.edu/relig_faculty

Part of the Religion Commons

\section{Repository Citation}

Dupertuis, R. R. (2012). Translating the Bible into pictures. In C. Vander Stichele \& H. S. Pyper (Eds.), Text, image, and otherness in children's Bibles: What is in the picture? (pp. 271-289). Society of Biblical Literature.

This Contribution to Book is brought to you for free and open access by the Religion Department at Digital Commons @ Trinity. It has been accepted for inclusion in Religion Faculty Research by an authorized administrator of Digital Commons @ Trinity. For more information, please contact jcostanz@trinity.edu. 


\title{
Translating the Bible into Pictures
}

\author{
Rubén R. Dupertuis
}

I became interested in the intersection of comic books and Bibles for children as a part of my attempt to make some sense out of the Brick Testament, a web-design project illustrating scenes from biblical stories entirely in the medium of Lego blocks. Despite the ostensibly child-friendly nature of the images - Legos are, after all, a children's toy-the project has a sharp critical edge to it. We catch a glimpse of it in the index, which has content ratings alerting viewers to which scenes contain "Nudity, Sexual activity. Violence and Cursing." Indeed, what Smith chooses to illustrate from the Bible emphasizes its "adult-themed" content by highlighting the violence, sexuality, and oddity of its content. Much of the material typically omitted or cleaned up for children's editions of the Bible is not only present in the Brick Testament, but is illustrated in great detail. One finds, for example, scenes illustrating the rape of Dinah (from Gen 34:1-34), Noah's drunkenness (9:18-29), and the beheading of John the Baptist, including an image of John the Baptist's recently severed head on a platter (Mark 6:20-29; Luke 3:19-20). ${ }^{\text {T}}$ Thus, given Smith's illustration choices, it is hard to see the Brick Testament as a children's Bible. That said, in my judgment the Brick Testament is not unrelated to the tradition of illustrated Bibles. Because many if not most of the illustrated Bibles produced in the twentieth century are meant for children, the Brick Testament can be read as a critique of or reaction against ways in which the Bible is presented to children.

Regarding the purpose of the project, Smith states that, in the end, "illustrating the Bible in Lego has been, for me, a chance to retell these stories in a way that's more faithful to the text than the other illustrated Bibles I've seen" (James 2003). If the Brick Testament is a reaction to this tradition, it is worth looking at it alongside some examples of illustrated Bibles

. Online: www.thebricktestament.com. 
for children. I have chosen Bibles that fall generally into the category of comics because, while the Brick Testament is not technically a comic book. it is clearly borrowing the general form, language, and esthetics of that medium by the use of sequential frames to convey a story through the use of images, captions, and word and thought bubbles. I have also chosen to focus on the presentation of the story of Cain and Abel from Gen 4:1-16 in several different Bibles, in part because this story regularly features in most relatively recent Bibles for children, but also because it is a narrative that presents any translator with a number of difficult decisions.

In what follows I first address my approach to comic-book Bibles and the Brick Testament principally as translations. I then examine the presentation of Gen 4:1-16 in three comic-book Bibles before turning to some aspects of the Brick Testament in general and its presentation of the Cain and Abel Story in particular.

\section{Comic-Book Bibles as Tiranslations}

While a number of different approaches to this material would be fruitful, including retelling and adaptation among many, I have chosen translation for several reasons. The first is the nature of what can be referred to generally as "the comics medium" itself. The wide range of what has been considered and presented as children's Bibles includes retellings of a handful of stories, catechisms, epitomes, summaries, and various illustrated and picture Bibles (Bottigheimer 1996, 3-13). Comic-book Bibles, a relatively recent phenomenon, certainly fit within the tradition of illustrated or picture Bibles, but they also present some distinctive features and challenges. ${ }^{2}$ Clear definitions of "comics," "comic books," and "graphic novels" are notoriously difficult to come by, but one of the most useful and well known is that of McCloud, for whom comics are "juxtaposed pictorial and other images in deliberate sequence, intended to convey information and/or to produce an aesthetic response in the viewer" $(1993,20)$. It is worth emphasizing the image-driven nature of the medium, as is thinking of images or icons in broad terms. While for some, comics are a combina-

2. While precursors abound, comics emerge in force in the twentieth century. For a very brief history of the medium, see Saraceni 2003, 1-3; for a more extensive history, see Harvey 1996.

3. I use these terms interchangeably, although I recognize that many will draw more fine distinctions. tion of language and images (Saraceni 2003, 5), for McCloud and others the images, icons, and symbols used to convey meaning in the medium are signs in the same way that the letters of an alphabet are. The comics medium is, in fact, increasingly being viewed as a language system that has developed a set visual vocabulary that requires a particular literacy on the part of the reader. ${ }^{4}$

It is also worth noting that in comics the images or pictures do not simply illustrate the text or the story, but are a central means through which the medium conveys meaning. Comics can, in fact, be thought of as a "hybrid word-and-image form in which two narrative tracks, one verbal and one visual, register temporality spatially... Highly textured in its narrative scaffolding, comics doesn't [sic] blend the visual and the verbal-or use one simply to illustrate the other-but is [sic] rather prone to present the two nonsynchronously; a reader of comics not only fills in the gaps between panels but also works with the often disjunctive back-and-forth or reading and looking for meaning" (Chute 2008, 452). If the comics medium consists of a language, then presenting or telling a Bible story in this medium can be considered a translation.

A second reason lies in the fact that what little critical attention comicbook Bibles have received has all been relatively recent and has, in one way or another, addressed translation issues. Beard and du Toit (2005), for example, examine children's Bibles, including "picture" Bibles, in South Africa explicitly as translations through the framework of cognitive poetics. Burke and Lebron-Rivera (2004) explore the possibility of reading a recent graphic-novel production of the story of Samson as midrash. They never use the term "translation," but their central concern is with the "transfer of Scripture" into the graphic-novel format, evaluating the level of accuracy of the graphic novel by comparison to the story of Samson in the Masoretic Text. Responding to Burke and Lebrón-Rivera, Clark also takes up the analysis of recent graphic-novel versions of the story of Samson. The concern with the "faithful transfer" of Scripture is even clearer here, as

4. Examples of this visual vocabulary include the ways in which "motion lines" or "zip ribbons" have been used to connote movement in a single frame, the use of posture and gesture, and even the use of particular icons to indicate certain types of speech (word balloons versus thought balloons). For a discussion of the challenge of representing movement in the comics medium, see McCloud 1993, 108-17. For the use of posture and gesture, see Eisner 2008, 103-14. 
Clark (2007) notes places where the transfer of meaning was "unfaithful" and where it hits the mark.

A third reason is that fidelity in translation is also a goal of many of the comic-book Bibles themselves. This is the case, for example, in the comic-book Bible series put out by the United Bible Society. In an article published in Bible Translator with the aim of introducing potential translators to the conventions of comics, Mundhenk says that "the series of Bible comics is an attempt to adapt the message of the Bible in a way that is both faithful to the message of the Bible and also faithful to the comics format" $(2002,413)$.

The self-presentation of most of the comics I examined for this study also invokes fidelity to Scripture. The back cover of one comic-strip version of the Hebrew Bible attributes the following endorsement to a prominent Christian leader: "Parents will do their children a real spiritual service by providing them with Picture Stories from the Bible. The stories follow the text of Scripture very closely" (Gaines 1979). Another authority says of the book: the author "has put the Bible stories into the modern comic form without sacrificing the accuracy of the Biblical text, and with all due reverence." Although less explicit about being a translation, the Comic Book Bible also presents itself as a kind of Bible starter kit translated into "picturebook" form in order to be attractive and understandable to children (Suggs 1997, back cover). And as I noted above, fidelity to the biblical original is also part of the Brick Testament's presentation. Smith says of his project: "For me, it's all about making the content of the Bible more acces. sible without changing that content" (James 2003). Although, as I note below, Smith's purpose in accurately representing the content of the Bible may ultimately be ironic, the claim of accuracy is there, thus legitimating the project by evoking popular notions of translation.

My own interest in approaching these texts as translations is twofold. The first concerns the type of translation that comic-book Bibles represent. Jakobson distinguished three kinds of translation: (1) interlingual translation-what is typically thought of as "translation proper"-in which the signs from one natural language (such as Hebrew or Greek) are interpreted by means of signs in another natural language (such as Spanish or English); (2) intralingual translation, in which the signs of one language are interpreted by means of other signs in the same language-essen. tially paraphrasing; and (3) intersemiotic translation, the interpretation of verbal signs by means of a nonverbal sign system $(1959,233)$. Comicbook Bibles are, or at least can be, all three types of translation. While the potential for interlingual translation exists, most comic-book Bibles start with an existing English language translation. ${ }^{5}$ What parts of the biblical text they render in what lakobson calls "natural language," whether that be rewording, paraphrasing, retelling, or something else, could be seen as intralingual translation. Certainly the use of images and icons would qualify as an intersemiotic translation. This last type is probably the most useful of the three for our purposes, but it is worth noting that the comics medium defies simple characterization.

I am also interested in the models of translation invoked, or better yet, assumed, when discussing comic-book Bibles. The focus on the fidelity of comics in their representation, retelling, or transiation of biblical stories often appears to assume a rather simplistic model of translation that, in my judgment, may be overly optimistic about the possibility of capturing the objective essence of the original into the target language or medium. Indeed, one of the central developments of translation studies in the last few decades has been dispelling the notion that the mark of a good translation is whether it is accurate (Williams 2004). Much of recent translation theory reflects the understanding that translations are always complex cultural transactions (Porter 2001). As Venuti puts it, translations are "the site of many determinations and effects-linguistic, cultural, economic, ideological" $(1995,19)$. But if the undistorted transfer of meaning is not fully possible, what then is the role of the translator, and what makes a good translation? For Venuti, while some violence is unavoidable in the act of translation, translators have a choice between two tendencies. One possibility is performing what he calls a "domesticating" translation that privileges the values and cultural assumptions of the target-language reader. Domesticating models of translation, Venuti argues, are dominant in English-language translation. This applies to most contemporary English translations of the Bible, perhaps especially those aimed at niche markets. In addition to presenting the biblical texts in attractive, accessible,

5. See the discussion of this issue in the context of the production and translation of children's Bibles in South Africa by Beard and du Toit $(2004, \$ 4.5)$. In regard to the Brick Testament, Smith notes on his site that in earlier stages of the project he drew almost exclusively from the N/B, but because of copyright issues, he changed the word. ing based on translations in the public domain and the recommendation of friends with knowledge of the original languages (online: http://www.thebricktestament.com/ fag/index.html). The biblical quotations that appear on every page of the Comic Book Bible appear to be taken from the $\mathrm{kJV}$. 
and understandable ways, they erase the cultural distance between the Bible and the present day, enlisting it (and the attendant authority of the Bible) in the maintenance and reification of contemporary cultural structures and ideologies.

For Venuti, the other possibility is foregrounding the cultural distance from and otherness of a source text by adopting a "foreignizing" translation. This is not a claim to be able to capture objectively some essence in the source text, because in the end the text's otherness is still rendered by means of the terms of the target language. The point, however, is "to develop a theory and practice of translation that resists dominant targetlanguage cultural values so as to signify the linguistic and culture difference of the foreign text" $(1995,23)$. With these possibilities or tendencies in mind we can take a look at how the Bible is translated in comic-book Bibles for children.

Cain and Abel in the Primeval Epic and

COMIC-BOOK BIBLES fOR CHILdREN

I will focus on the story of Cain and Abel in Gen 4:1-16, a staple of recent children's Bibles. While there are numerous interpretive difficulties in this little story-as evidenced by the complex history of interpretation ${ }^{6}$-in my reading of the story there are four issues in particular to which I want to pay attention. The first is the apparent arbitrariness of God's choice of Abel's sacrifice over Cain's. The choice is not explained or justified in the Hebrew Bible. Both Cain and Abel make offerings from what is appropriate to their occupation-Cain the farmer, Abel the shepherd. As Brueggemann notes, "The trouble comes not from Cain, but from Yahweh-the strange God of Israel. Inexplicably, Yahweh chooses-accepts and rejects" $(1982,56)$

The second interpretive issue is the first interaction between God and Cain immediately after the latter's sacrifice is not accepted and "his countenance fell" (Gen 4:5). In the wake of God's arbitrary preference for Abel's sacrifice, the reminder that doing well leads to acceptance, while not doing well opens one up to sin is hardly comforting since it is unclear what Cain did wrong in the first place $(4: 6-7)$. At best this, too, is another enigmatic

6. See, e.g., the discussion of Gen 4:1-16 in Westermann 1984, 279-320. See also Lohr 2009, who traces the history of interpretation of this passage as far back as the Septuagint translation of the Hebrew Bible. feature of the story. At worst, God is not playing fair and is toying with Cain (Brueggemann 1982, 57). The third issue is God's second interaction with Cain, in which Cain is cursed, his connection to the ground severed, and he is destined to live as an exile and a wanderer. Cain's protest results in a form of accommodation: a mark protecting him from harm. The literary function of this mark on Cain is "two edged. On the one hand, it announces the guilt of Cain. On the other, it marks Cain as safe in God's protection" (Brueggemann 1982,60). And the fourth issue I want to highlight is the violence that is at the heart of the first murder in the Bible. As with much in this terse, brief narrative, the pivotal moment is striking for its brevity: Cain invited Abel to a field where he "rose up against his brother Abel, and killed him" (4:8 NRSv).

Of the numerous publications that would fit under the category of comic-book Bibles, I have chosen to focus on three. The first, the Comic Book Bible by Rob Suggs, is a Christian publication (as are the other two examples on which I focus) that aims at an audience of children from ages eight to twelve and tells selected stories from both the Hebrew Bible and the New Testament. ${ }^{7}$ In the Comic Book Bible the story of Cain and Abel is told in six panels on one page. At the top of each page is a Bible verse related to the story, a choice that may be related to an anxiety often seen in illustrated or picture Bibles over the relationship to the text of the Bible (Bottigheimer 1996, 39). In this case, the words selected from the Cain and Abel story are from Gen 4:4-5: "And the LoRD had respect for Abel and his offering, but unto Cain and to his offering he had not respect." This choice highlights the importance of God's preference of the sacrifice of one brother over the other, which in the Hebrew Bible is enigmatic if not arbitrary.

In the Comic Book Bible, however, God's preference for Abel's sacrifice is anything but arbitrary. One way in which this is achieved is the dialogue supplied to the characters. In the first frame of the story Abel says, "I'll offer the best of my flock"; while in the next frame, Cain states, "Abel is always sacrificing. Maybe this old plant will do for me" (fig. 12.1). The order in which the sons are introduced and offer their sacrifices is reversed from the order in the Hebrew Bible, effectively making Cain play catch-up and introducing the notion of jealousy. The words ascribed to

7. Unless otherwise noted, all references to the Comic Book Bible are to p. 13, which contains the six frames of the story of Cain and Abel. 
the brothers emphasize the importance of the proper attitude during worship. In addition to making clear the superior quality of Abel's sacrifice, the story also suggests that God's choice is understandable. In the second frame Cain says, "Abel is always sacrificing"; and in the third he thinks, "As usual, God liked Abel's sacrifice better, well I'm sick of it." In this story Abel apparently sacrifices more often, his offerings are better, and God routinely chooses the sacrifice of Abel over that of Cain. The justification of God's choice is also done visually. Abel is introduced in the first frame as the cute, bright-eyed younger brother active in tending his flock, while Cain bears a droopy moustache (a permanent frown?) and stands idle in the background leaning up against a tree. We see Abel's face again in the third frame-again he is smiling while his brother, watching him out of the corner of his eyes, thinks jealous thoughts. Whatever insight Cain's thoughts and words give the reader about his motivations, visually he is typed throughout as a villain.
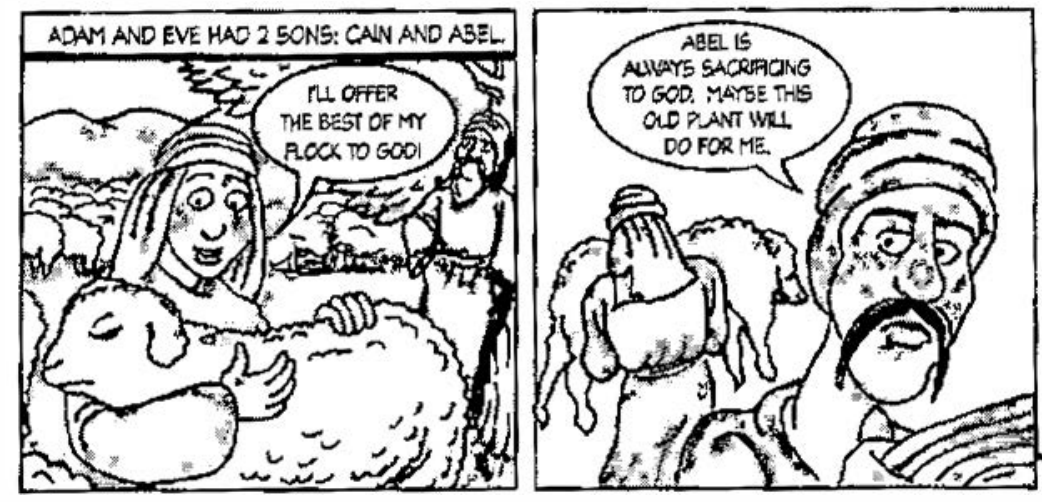

Fig. 12.1. The Comic Book Bible (Suggs 1997, 13).

The first interaction between God and Cain before the murder of Abel is omitted entirely, while in the presentation of the second there is no indication that God's punishment of Cain for the murder of his brother with exile is accompanied by a way of protecting him against those who would do him harm. Here it is simply a punishment. This story is about a young man with a bad attitude (and bad facial hair) who succumbs to jealousy, kills his brother, and suffers a corresponding punishment. Finally, the Comic Book Bible avoids the violence in the story, showing a frame of
Cain's ambush of Abel, then going directly to God's second encounter with Cain. This is not surprising, as violence and perceived amoral actions in children's Bibles have been reworked or omitted for the better part of the last two centuries (Bottigheimer 1996, 54; Schine Gold 2004, 124-33).

An earlier comic-book Bible for children touches on many of the same themes. Published originally in 1942, Picture Stories from the Bible by M. C. Gaines has stories from both the Old and New Testaments in two separate volumes. Its version of the story of $\mathrm{Cain}$ and $\mathrm{Abel}$ is longer, told over fourteen frames $(1979,8-10)$. As is the case in the Comic Book Bible, in Picture Stories the reason for God's choice between Cain and Abel is made abundantly clear. After the brothers and their respective occupations are introduced, a caption states: "One day Abel decided to make an offering to the Lord-Cain pledged an offering too, but his heart wasn't in it." Below the caption is a scene of Cain and Abel flanking Adam at the dinner table in which Abel says, "For God's goodness I feel I should sacrifice a lamb from my flock to him!" Cain, however, states, "Oh well, I can offer him some of my fruit." The next frame depicts Cain watching Abel prepare his sacrifice, thinking, "I'll not be outdone by my brother." The frame in which God's choice is conveyed begins with the following caption: "God, looking into their hearts, commends Abel but not Cain."

Here the point is that attitude matters and that jealousy is the reason for God's rejection of Cain, and again the order in which the brothers offer their sacrifices is reversed. An interesting aspect of this Bible is the emphasis on God's ability to see into the brothers' hearts, something noted specifically in the caption and underscored by visual representation of the brothers. Unlike the Comic Book Bible, where the superiority of Abel is clear visually, here the two brothers are from the beginning virtually identical. The initial frame of the story depicts them as young children, featuring Cain climbing a tree while expressing his desire to watch things grow when he grows up, and Abel expressing his desire to be a shepherd while on the ground petting a sheep. All subsequent frames have the boys as adults; they are thickly muscled, idealized, and indistinguishable from each other except for Cain having a thin headband. Their physical similarity serves to call attention to God (who like the comics reader is privy to the characters' thoughts) knowing people's hearts and not being fooled by outward appearances.

Other choices in Picture Stories are also worth noting. The first interaction between Cain and God is presented here, but it is framed by Cain "slinking" away, muttering jealous words-something both visually 
depicted and stated in a caption - and a running Cain shouting, "You jusi wast." Cain's murder is here portrayed in more detail than in the Comic Book Bible in a frame with a caption reading, "They came to a field and suddenly Cain attacked and killed Abel." Below the caption Cain has Abel in a headlock with one arm, while in the other is a large stone ready to strike. The actual moment of Abel's murder is not shown, and the story quickly moves on. Picture Stories is one of the few comic-book Bibles for children to present the double-edged nature of God's second and final encounter with Cain. The final frame of the story depicts a downcast Cain protesting his punishment, particularly his fear that being a "fugitive and a vagabond" would get him killed, and a response from God: "I shall set a mark upon you lest they do this, and it shall be the brand of Cain." The brief explanation feels a bit more like an etiology for the "brand of Cain" than an emphasis on the idea that Cain is both punished and protected. Furthermore, the protection by God is necessary given the Picture Bible's choice to narrate the story of Cain taking a wife and becoming the father of Enoch. The inclusion of this material drawn from Gen 4:17 is unique in the comic-book Bibles for children I examined.

A very different treatment of the story of Cain and Abel can be found in the recent Manga Bible series from Zondervan, which has a volume dedicated to Genesis and Exodus entitled Names, Games, and the Long Road Trtp (Lee and Hiwang 2007). A more cartoony version clearly aiming at humor, this Bible is much more self-conscious in being a representation of biblical stories and is missing the somber tone of some of the other versions. The Marga Bible lingers over the events of Gen 4:1-16, devoting to it thirty frames over four and a half pages (for comparison, the much longer story of the flood in Gen 6-9 gets only thirty-five frames over six pages). Like the Comic Book Bible, the Manga Bible makes the superiority of Abel visually clear. Cain, drawn as an aduit with angular features and spiky hair, is an unhappy thug. The first frame depicting Cain as an adult has him reaping grain with a sickle while complaining that "farming is too hard." The much younger Abel, on the other hand, is a cute kid with a round face and bowl haircut who is introduced to the reader in a frame depicting him holding a small sheep and saying, "Sheep are so cute." The only frames in which Cain is smiling are those in which he is planning and carrying out his plan to kill his brother and believes he has tricked God by hiding the body of the murdered Abel. Given the clear visual labeling of Cain as a bad guy, God's preference for Abel's sacrifice is not surprising. Aside from the rather generic labeling of Cain as a villain, the reason for God's prefer- ence for Abel's sacrifice is more narrowly defined as Cain's greed. Here the issue is not necessarily the right attitude or what is in one's heart, but how much one gives to God: Cain is shown reconsidering how much to give to God as a sacrifice, finally offering a minimal amount after reasoning that he couldn't "give [Cod] an empty dish." While humor is clearly the aim, the message is clear: Cain's sacrifice was unacceptable in its quantity, not its quality.

The first interaction between Cain and God immediately following the rejection of Cain's sacrifice is represented in the Manga Bible in four frames that stand out for their more sophisticated use of the language of the comics medium (fig. 12.2) - motion or zip lines indicate Cain's confusion at the rejection of his sacrifice, sound effects indicate his anger as he cracks his knuckles, and finally God's voice irrupts in to a frame asking Cain questions that are a paraphrase of Gen 4:6-7. Tired of being picked on, Cain decides that God's disfavor is Abel's fault and begins to plot his murder.
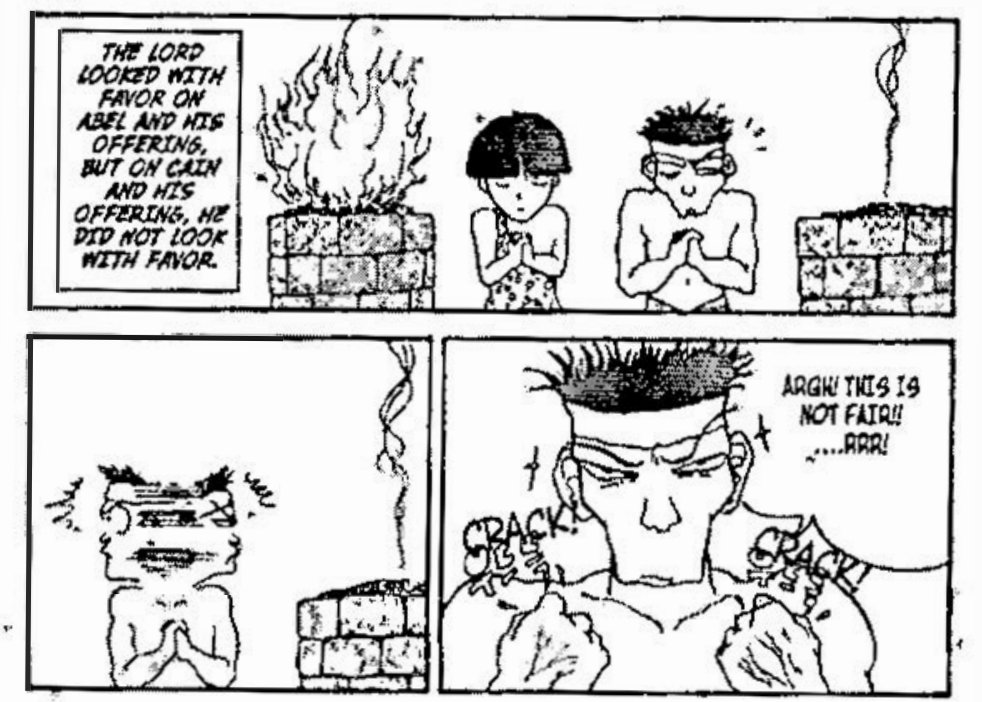

Fig. 12.2. The Minnga Bible (Lee and Hwang 2007, 14).

Here, too, the violence of Cain's murder is presented more graphically than in the Comic Book Bible, but it is still suggested rather than shown. Four frames portray Cain luring Abel out into a field, a fifth shows only the top of Abel's head while above him looms Cain with a large rock in his hands. Finally, while the Manga Bible does suggest that Cain is both cursed 
and protected, it appears to be uncomfortable with God's protection of Cain and has him earn it with "tears of repentance."

As translations these Bibles are clearly on the domesticating end of the spectrum, but that is precisely the point. The stated goal of these comics is, in some way or another, to make the Bible accessible and fun for children. Several aspects about how this is done are worth noting. What is portrayed, including how it is portrayed, is filtered through contemporary beliefs about what is appropriate for children. This includes the decision to turn stories full of ambiguity into clear articulations of contemporary morals. But since what is deemed appropriate social behavior varies, it is worth noting the different reasons given for God's refusal to accept Cain's sacrifice. Both the Comic Book Bible and Picture Stories emphasize Cain's lack of appropriate attitude and jealousy, while the Manga Bible highlights Cain's laziness and, in particular, his greed - he simply did not give enough. Particular details may differ, but that these Bibles serve to reify contemporary values and morals places them squarely within the long tradition of childrer's Bibles (Bottigheimer 1996).

'Ihe visual aspects of how the biblical stories are represented are also clearly shaped by the concerns of the contemporary target culture. That almost all comic-book Bibles are in color says something about the younger audience these publications are targeting. Historically, most comics are in black and white. 'Ihe exceptions are the more recent publicalions, including the Manga Bible series by Zondervan, which appear to be designed specifically to appeal to readers already interested in the comics medium. One could argue that giving all of the biblical characters some measure of recognizable ancient clothing represents a foreignization of sorts, highlighting the distance between the biblical and our contemporary worlds. The effect, however, is one of domestication as the foreign or ancient clothing works along the lines of contemporary notions of what is ancient or primitive (much like the elaborate sets of the "sword and the sandal" films produced by Hollywood). Furthermore, all biblical characters are portrayed as recognizably white, despite their ranging from fairly detailed to relatively abstract. ${ }^{8}$

This last point is worth elaborating. When it comes to the use of the comics medium, my initial judgment was that these comics are not very

8. Again, the Manga Bitzie may be the exception. Clear identification of the ethnicity of the characters is difficult, which may, of course, be intentional. good-at the very least they do not represent a very sophisticated use of the comics medium. This is less applicable to the more recent publications that appear to be much more aware of and willing to make use of the lexicon of the medium. Of the comic-book Bibles discussed above, I would lighlight the Manga Bible as the most sophisticated. But even the rather simplistic art of the others can have a particular function in the comics medium. McCloud argues that one of the key aspects of good comics art is identification on behalf of the reader with particular narrative characters. Identification, something that is also a part of exclusively textual narratives, is complicated in this case by comics typically visually representing people, and not all of us look the same. He argues that the more specific and detailed a representation of a particular person becomes, the fewer the number of people who can readily identify with the character ( $1993,24-59)$.

Applied to comic-book Bibles, it might be argued that the rather simplistic art functions as a way of allowing greater identification. This does not necessarily work for Picture Stories, where the decision to render Cain and Abel in identical, adult, hypermasculine bodies and fairly detailed facial features does not facilitate identification. If anything, Cain and Abel represent a distant, idealized past. As I noted above, that the brothers are nearly indistinguishable also underscores the point that God knows people's hearts and that proper attitude is what determined God's preference of Abel over Cain. Identification is key, however, in the other two comicbook Bibles, where the character of Abel is much younger and drawn more simply or even abstractly than his brother. In the Manga Bible, for example, the character of Abel is a cute, somewhat generic good kid, while the character of Cain is so wholly othcr, so monstrous, that any possible sympathy, let alone identification, is made impossible.

\section{Critiquing tile Illustrated Bible Tradition BY ILLUSTRATING THE BIBLE}

Because Bibles for children, including illustrated or picture Bibles, are for the most part produced for didactic purposes, they tend to follow fairly consistent patterns in the stories they select and how these stories are presented. The Brick Testament, Smith's ongoing web-design project illustrating biblical storics using only photographed Lego blocks, can be read as a critique of this tradition. Begun in 2001, by 2003 the site had received enough interest to lead to the publication of a coffee table book entitled 
The Brick Tectament: Stories from the Book of Genesis. Smith published two more books in 2004 and has continued to add scenes to his online site. The website, which is my focus here, now has illustrations for much of the Bible.'

While Smith notes that his images are often used in church settings for educational purposes, the critical, if not satirical, edge of his project is readily apparent. What is of interest here is how this critique is carried out. 'The Brick Testament inhabits a carefully negotiated space at the intersection of a number of genres, styles, and sensibilities. Part comic book, part Bible illustration, part photography, part interactive online experience, Smith intentionally plays off of the conventions of all of these genres and media. But he plays with these conventions, particularly those of the comiss medium, in ways that highlight the cultural otherness, occasional oddity, violence, and cleariy "adult-themed" content of much of the Bible. It is, in a way, a sustained project of foreignization.

I take two of its central ideas to be a critique of literal readings of the Bible and an emphasis on the otherness or foreignness of the Bible. Smith critiques literal readings of the Bible by adhering to a strict literalism himself. In every frame the image is accompanied by the text being illustrated, effectively functioning as a caption. This can be read as a desire to follow Scripture closely; indeed, Smith claims that his illustrations remain "true to the text of the scriptures." 10 In most frames, however, this literalism creates a redundancy that effectively stilts the narrative. Because the comics language depends on both a textual and visual register, in this medium adaptations of biblical narrative that keep much or most of the wording of a biblical account are rare."

In the Brick Testament's version of the Cain and Abel story, the encounter between God and Cain immediately after the murder begins with a frame illustrating the following part of Gen 1:9: "Yahweh said to Cain,

9. To my knowledge, changes to the website have typically been limited to filustrations of new material. Recently, however, Smith has revisited some of his early illustrations of Genesis, including his treatment of the story of Cain and Abel. My study of Smith's work is based on the original Illustrations of Genesis that were displayed on the site from 2001 to 2010.

10. Online: www.thebricktestament.com/faq/index.html.

11. Giving potentlal translators of the United Bible Society comic-book Blbles guidelines on how to translate into the comies medium, Mundhenk recommends that when possible, the story should be carried by illustrations alone, with balloons being preferred over captions $(2002,406)$
'Where is your brother Abel?' 'I don't know', he replied." In the illustration above the text the dialogue is placed in word balloons, thus reproducing it twice on the page. ${ }^{12}$ The effect of this redundancy is magoified in the remaining frames, which reproduce the final encounter between Cain and God almost in its entirety, including instances of rather lengthy speech by God. The end result is humorous in part because of its clunsiness and redundancy. As comics narrative, however, it is awkward if not just plain bad. But because Smith is presumably carrying out a narrative illustration that is "faithful" to the text of the Bible, the ultimate source of the awkwardness, then, is presumably the Bible itself.

Smith also appears to delight in capturing those places where this literalism produces surprising, odd, or humorous results. Such is the case in his illustration of Gen 9:28-29. Smith illustrates the majority of these two verses, which note the years that Noah lived after the flood and the total number of years he lived, in one frame in which Noah and his wife stand next to each other holding hands. The next frame illustrates the words "and he died" in a scene in which Noah is lying on his back while his wife, still standing, looks down on him. Literalism followed to absurd ends can also be seen in Smith's illustration of Mary's hymn of praise in Luke 1:46-55. Smith illustrates each of the attributes ascribed by Mary to God. The words "he has scattered the proud and arrogant," he illustrates with an image of God shooing a number of people away; "He has cast down rulers from their thrones," he illustrates with an image of God throwing a king off a chair; and that God "has raised up the lowly", is accompanied by an image of God holding three men with tattered clothing above his head. By following literalism to a fault, Smith is able to highlight just how much typical translations (and illustrations) do to make the text intelligible in our contemporary contexts.

The emphasis of the Brick Testament on what might be called the otherness of the Bible itself comes through in its retclling of the Cain and Abel story. Where most comic-book Bibles work hard to make the story relevant to contemporary sensibilities, particularly along the lines of what is deemed acceptable for children, the Brick Testament seems to push in the opposite direction. By the midtwentieth century, traces of sexuality were removed not just in Bibles for children but in children's literature more generally (Schine Gold 2004, 127-28). Accordingly, direct representations

12. Online: www.thebricktestament.com/genesis/cain_and_abel/gn04_09a.html. 
of Adam's "knowledge" of Eve and her subsequent conception of Cain in Gen 4:I are usually avoided in Bibles for children.

Smith, however, begins by sidestepping the euphemism of 4:1, preferring to depict the first couple having sex..$^{13}$ As noted above, the violence in the story is typically omitted or downplayed in children's Bibles; however, the Brick Testament focuses on it. 'The text of $4: 8$ is, "Cain said to his brother Abel, 'Let us go out to the field.' And when they were in the field, Cain rose up against his brother Abel, and killed him" (NRSv). Smith illustrates this one verse over three frames, the first depicting Cain asking Abel to join him in the field while concealing a knife, the second showing Cain attacking Abel, and the third frame corresponding to the text, "And he killed him," showing the slain Abel in a pool of blood (represented by blocks of translucent red Legos). Not only does Smith depict the primeval epic's first murder, but he seems to linger on the violence of the narrative.

What remains of the story is told in seven frames, all of which portray the final encounter between Cain and God. In four of the seven the slain body of Abel is visible in the background. ${ }^{14}$ The ambiguity in the story, both in God's preference for Abel's sacrifice and the double nature of the mark given to Cain, is kept. This is due, in part, because Smith has chosen to illustrate almost all of 4:1-16. But it is worth noting that the interpretive difficulties of the ambiguity suit Smith's agenda well.

Judged in terms of the conventional application of the comics medium, Smith's translation of the Bible is a bad one, but intentionally so. What aspects of comics he appropriates, he appears purposef ully to use ineffectively - the redundancy of the captions and the text in the word bubbles, for example-in order to highlight the otherness of the Bible. He uses the esthetics of the medium to illustrate that if followed closely the Bible itself is very different from what one expects. He consistently highlights instances of sex and violence in the Bible, but he also illustrates nonnar-

13. The English translation below the Illustration also avoids the euphemism: "The man had sex with his wife Eve" (online: www.thebricktestament.com/genesis/ cain_and_abel/gn04_0Ia.html).

14. A similar approach is taken in the Brick Testament's version of the flood in Gen 6-9. Smith emphasizes that some anlmals did nat make it into the ark. He also emphasizes the human loss in the story: the frame illusirating the moment in which Noah and his family cmerge from the ark as the waters recede showcases the skeletons of those who did not make it into the ark. rative material not typically part of the tradition of children's Bibles. ${ }^{15}$ The legal materials in the Hebrew Bible do not translate well into comics narrative, but they do give Smith the opportunity to illustrate an instance of bestiality. ${ }^{16}$ Smith's project appears designed to force people to take a look at what is really in the Bible. And the shock value of much of the Brick Testament depends on fairlystable patterns in the presentation of the Bible for children. This is emphasized by the choice of a medium often associated with children and the use of Lego blocks.

The Brick Testament can be fairly viewed as an extended project of foreignization in the sense that Smith is able "to signify the linguistic and cultural difference of the foreign text" (Venuti 1995, 23) -in this case the Bible. But the thrust of Smith's project is a reaction to contemporary translations, retellings, and interpretations of the Bible that he feels have misrepresented what is in it. This reaction is a domestication in its own right, because the force of the critique, the oddity and otherness he is trying to point out in the Bible, depend on contemporary assumptions of what is culturally acceptable and normative, what is odd and weird. It depends also on the absence of context.

\section{Conclusion}

The Brick Testament is at times very funny, smart, and even insightful in some of its critique. At its best, Smith effectively highlights how much modern translators/interpreters have to do to make the Bible intelligible and applicable in contemporary contexts. And Smith is right, too, in pointing out the adult-themed content of much of the Bible. That the Bible is not a children's book is clear to anyone who has wrestled with telling some of its stories to astute, young interpreters. A recent reminder of this came as I read one of the comic-book Bibles I studied for this project with my five-year-old daughter and I found myself trying to explain why Jesus could throw tables in the temple when he was angry but she couldn't. Smith is right, of course; the Bible is not a children's book, but here I sympathize with the attempts of the comics and other children's Bibles to present some of these stories to children in interesting ways. The problem, for

15. The working definition of children's Bibles adopied by Bottigheimer from Sybille Peter-Perrett: "Prose re-workings of the narrative sectiosss of the Bible for child readers," makes clear the emphasis on narrative in the tradition $(1996,4)$.

16. Online: www.thehrichtestament.com/the_law/beastiality/lvl8_23a.html. 
me, comes in the claims to accuracy and fidelity. Given the authority of the Bible in many contemporary settings, these claims are probably rhetorically expedient, but ultimately not very helpful-translation is far too complex a phenomenon for that. So is there a place for comic-book Bibles for children? In my judgment there certainiy is. But perhaps the Brick Testament is reflecting frustration with the fact that for many the Bible is not allowed to grow up.

\section{WORKs Citre}

Beard, Luna, and Jaqueline S. du Toit. 2005. "A Proactive Approach to the Translation of Bible Stories for Children." META: Translator's lournal 50.4. Online: http://id.erudit.org/iderudit/019830ar.

Bottigheimer, Ruth B. 1996. The Bible for Children from the Age of Gutenberg to the Present. New Haven: Yale University Press.

Brueggemann, Walter. 1982. Genesis. Interpretation. Atlanta: John Knox.

Burke, David G., and I.ydia Lebrón-Rivera. 2004. "Transferring Biblical Narrative to Graphic Novel." SBL Forumn. Online: htty.//sbl-site.org/ Article.aspx?ArticleID $=249$.

Chute, Hillary. 2008. "Comics as Literature? Reading Graphic Narrative." publications of the Modern Language Association 123:452-65.

Clark, Terry Ray. 2007. "Biblical Graphic Novels: Adaptation, Interpretation, and 'Faithfill Transfer." SBL Forum. Online: http://sbl-site.org/ Article.aspx?ArticleID $=641$.

Eisner, Will. 2008. Comics and Seqquential Art: Principles and Practices from the Legendary Cartoonist. New York: Norton.

Gaines, M. C. 1979. Picture Stories from the Bible: The Old Testament int Full-Col or Comic-Strip Form. New York: Scarf.

Harvey, Robert C. 1996. The Art of the Comic Book: An Aesthetic History. Studies in Popular Culture. Jackson: University Press of Mississippi.

Jakobson, Roman. 1959. "On Linguistic Aspects of Translation." Pages 232-39 in On Translation. Edited by Reuben A. Brower. Harvard Studies in Comparative Literature 23. Cambridge: Harvard University Press.

James, Meredith. 2003. "Building a Colorful, Accessible Bible, Brick by Lego Brick." Chicago Tribune, 30 November 2003. Online: http://www. thebricktestament.com/press/chicago_tribune_03_11_30.html.
Lee, Young Shin, and Jung Sun Hwang (ill.). 2007. Names, Games, and the Long Road Trip: Genesis-Exodus. The Manga Bible 1. Edited by Bud Rogers, Grand Rapids: Zondervan.

Lohr, Joel. 2009. "Righteous Abel, Wicked Cain: Genesis 4:16 in the Masoretic Text, the Septuagint, and the New Testament." CBQ 71:485-96.

McCloud, Scott. 1993. Understanding Comics: The Invisible Art. New York: HarperPerrenniel.

Mundhenk, Norman A. 2002. "I'ranslating Bible Comics." BT 53:402-13.

Niditch, Susan. Chaos to Cosmos: Studies in Biblical Patterns of Creation. Scholars Press Studies in the Humanities 6. Chico, Calif.: Scholars Press.

Porter, Stanley E. 2001. "Some Issues in Modern Translation Theory and Study of the Greek New Testament." CurBS 9:350-82.

Saraceni, Mario. 2003. The Language of Comics. Intertext. New York: Routledge.

Schine Gold, Penny. 2004. Making the Bible Modern: Children's Bibles antd Jewish Education in Twentieth-Century America. Ithaca: Cornell University Press.

Smith, Brendan Powell. 2003. The Brick Testament: Stories from the Book of Genesis. Philadelphia: Quirk.

--. 2004a. The Brick Testament: The Story of Christmas. Philadclphia: Quirk.

- 2004b. The Brick Testament: The Ten Commandments. Philadelphia: Quirk.

Suggs, Rob. 1997. The Comic Book Bible. Uhrichsville: Barbour.

Venuti, Lawrence. 1995. The Translator's Invisibility: A History of Translation. Translation Studies. New York: Routledge.

Westermann, Claus. 1984. Genesis 1-11: A Commentary. Translated by John J. Scullion. Minneapolis: Augsburg.

Williams, Alan. 2004. "New Approaches to the Problem of Translation in the Study of Religion." Pages 13-44 in Textual, Comparative, Sociological, and Cognitive Approaches. Edited by Peter Antes, Armin W. Geertz, and Randi R. Warne. Ncw Approaches to the Study of Religion 2. New York: de Gruyter. 